\title{
PROPOSTA DE REUTILIZAÇÃO DO RESÍDUO DE CERÂMICA VERMELHA PROVENIENTE DA CONSTRUÇÃO CIVIL E DEMOLIÇÕES NO MUNICÍPIO DE CRICIÚMA, SC
}

\section{PROPOSAL FOR THE REUSE OF CLAY CERAMIC WASTE DERIVED FROM CONSTRUCTION AND DEMOLITION IN THE CITY OF CRICIÚMA, SC}

\author{
Suelen Alexandre Possa ${ }^{1}$ \\ Elaine Guglielmi Pavei Antunes ${ }^{2}$
}

\section{Resumo}

A indústria da construção civil gera uma grande quantidade de resíduos, popularmente conhecidos como entulhos. Acaso não seja dado um destino correto a esses resíduos de construção e demolição (RCDs), eles podem trazer uma série de problemas ao meio ambiente. A construção civil é um dos setores que impulsionam a economia do município de Criciúma, atualmente um centro econômico muito importante do sul catarinense. Dentre os diversos tipos de RCDs gerados pelas construções destaca-se, nesse município, o resíduo de cerâmica vermelha. Com base nessas informações, esse estudo busca propor a forma mais adequada de reutilizar o resíduo de cerâmica vermelha e reinseri-lo na própria cadeia produtiva da construção civil, como: concretos, argamassas e pavimentação. Após análise, conclui-se que hoje a melhor forma de reaproveitamento do resíduo de cerâmica vermelha no munícipio de Criciúma é aplicálo em misturas de solo-agregado para camadas de sub-base em pavimentações de rodovias de baixo volume de trafego.

Palavras-Chave: Resíduos de construção e demolição, cerâmica vermelha, reutilização

\begin{abstract}
The construction industry is one sector that currently drives the economy of Criciúma, a very important economic center of southern Santa Catarina. Among the several types of RCDs (construction and demolition residue) generated by the construction of buildings in Criciúma, the clay ceramic residue is one that stand out. Based on this information, this study aims to propose the most appropriate way to reuse the clay ceramic residue and to reinsert it into the own productive chain, such as: concrete, mortar and paving. After analysis, it is concluded that the best way to reuse the clay ceramic residue is to apply it in mixes of aggregated soil that will be used on sub-base layers used on the flooring of low traffic volume roads.
\end{abstract}

Keywords: Residue of construction and demolition, clay ceramic, reuse

\section{INTRODUÇÃO}

O setor da construção civil é responsável por grande parte do desenvolvimento econômico e social do país. Em contrapartida, também é responsável pelo consumo significativo de recursos naturais não renováveis.

\footnotetext{
${ }^{1}$ UNESC - Universidade do Extremo Sul Catarinense. E-mail: suelenpozza@ hotmail.com

${ }^{2}$ UNESC - Universidade do Extremo Sul Catarinense. E-mail: elainegpa@ unesc.net
} 
O volume de recursos naturais utilizado pela construção civil, muitos deles não renováveis, corresponde a pelo menos um terço do total consumido anualmente por toda sociedade. O setor consome cerca de 210 milhões de toneladas por ano de agregados naturais somente para a produção de concreto e argamassas (JOHN, 2000, p. 23).

O setor atua como um dos grandes vilões na geração RCDs (resíduos de construção e demolição), popularmente chamados de entulhos. Esses resíduos são gerados desde a implantação do canteiro de obras até o término da construção. A Resolução 307 do Conselho Nacional do Meio Ambiente, CONAMA (2002, p. 01) define os resíduos de construção civil como sendo tudo aquilo que é proveniente de construções, reformas, reparos e demolições de obras de construção civil, e também os resultantes da preparação e da escavação de terrenos.

Rosa (2011, p. 7), enfatiza que esses entulhos estão sendo depositados em terrenos baldios à margem de estradas e rodovias ou até mesmo em áreas de preservação permanente (APP). Segundo Guadagnin e Peterle (2006, p. 05), essas deposições acabam trazendo problemas ao meio ambiente, contribuindo para a degradação ambiental, surgimento de agentes proliferadores de doenças, ocupação de vias e logradouros e obstrução dos sistemas de drenagem. O acúmulo desses materiais pode gerar risco de periculosidade, assoreamentos dos córregos e destruição das nascentes e olhos d'agua, além da própria poluição visual.

A Resolução 307/2002 CONAMA classifica os RCD de acordo com a tabela 1

Tabela 1 - Classificação dos RCD

\begin{tabular}{ll}
\hline Classe & Descrição \\
\hline & Resíduos reutilizáveis ou recicláveis como agregados, de \\
& construção, demolição, reformas ou reparos, tais como: a) \\
& pavimentação e de outras obras de infraestrutura, inclusive \\
& solos provenientes de terraplenagem; b) de edificações: \\
Classe A & componentes cerâmicos (tijolos, blocos, telhas, placas de \\
& revestimento etc.), argamassa e concreto; c) de processo de \\
& fabricação e/ou demolição de peças pré-moldadas em concreto \\
& (blocos, tubos, meios-fios etc.) produzidas nos canteiros de \\
& obras \\
Classe B & Resíduos recicláveis para outras destinações, tais como: \\
& plásticos, papel, papelão, metais, vidros, madeiras e gesso \\
Classe C & Resíduos para os quais não foram desenvolvidas tecnologias \\
& ou aplicações economicamente viáveis que permitam a sua \\
& reciclagem ou recuperação \\
Classe D & Resíduos perigosos oriundos do processo de construção, tais \\
& como: tintas, solventes, óleos e outros, ou aqueles \\
& contaminados oriundos de demolições, reformas e reparos de \\
& clínicas radiológicas, instalações industriais e outros. \\
\hline
\end{tabular}

Fonte: Resolução 307/2002 (CONAMA) 
Na composição do RCD, segundo Cabral (2008, p. 01), argamassa, concreto e materiais cerâmicos somam $62 \%$ do total de RCD das cidades brasileiras. Esses materiais são classificados como resíduos classe A, ou seja, resíduos reutilizáveis ou recicláveis como agregados (CONAMA 307/2002, p. 02).

Na região da AMREC, de acordo com Rosa (2011, p. 91), tem-se 204 áreas de descarte de RCD, sendo $71 \%$ consideradas de grande porte e a maioria dessas áreas se enquadra com um médio a grande potencial de reaproveitamento. $\mathrm{O}$ autor salienta ainda que, com relação ao tipo de resíduo presente nas áreas de deposição de RCD, destacamse os resíduos classe A, principalmente cerâmica vermelha.

Em pesquisa realizada por Fortuna et al. (2012, p. 113), em relação aos tipos de resíduos que são gerados por quatro grandes construtoras de Criciúma, SC, os autores afirmam que os resíduos gerados em maior quantidade são blocos e outros produtos cerâmicos.

Diante dos dados apontados acima, verificou-se que um dos resíduos mais descartados na construção civil, na cidade de Criciúma é o resíduo de cerâmica vermelha.

O setor cerâmico equivale a 1,0 \% do PIB brasileiro, sendo que só a cerâmica vermelha estrutural representa cerca de $40 \%$ desse valor e 4,8\% da indústria da construção civil (IBGE 2008). Segundo BUSTAMANTE e BRESSIANI (2000, p. 31)

\footnotetext{
Este segmento produz blocos cerâmicos furados, blocos cerâmicos maciços, tavelas ou lajes, blocos de vedação e estruturais, telhas, manilhas e pisos rústicos e movimenta ao redor de 60.000.000 de toneladas de matérias primas ao ano, com reflexo nas vias de transporte, e no meio ambiente de lavra de argila.
}

Uma pesquisa feita pela Universidade do Extremo Sul Catarinense (UNESC) em 2006, coordenada pelo Eng. Agrônomo M.Sc. Mario R. Guadagnin, sobre resíduos de construção civil em algumas construtoras da cidade de Criciúma, mostra que quebras de tijolos são muito significativas tanto na fase de assentamentos como na fase de instalação hidrossanitária de uma construção. A quebra se dá no manuseio, no transporte, na alocação em locais inapropriados e no corte do mesmo, feito na maioria das vezes sem nenhum procedimento adequado. Esse resíduo quando não é reaproveitado na própria obra é descartado pelas construtoras.

Diante da crescente quantidade de produção de resíduos e a elevada utilização de recursos naturais, Bastos et al. (2013, p. 3) salientam que o desenvolvimento de novos materiais esteja não somente ligado aos aspectos econômicos, mas também aos aspectos 
ambientais e sociais. Tal desenvolvimento deve-se basear no desenvolvimento sustentável e em modelos cíclicos de produção e consumo, onde os materiais possam voltar para as fases iniciais de produção após o fim de sua vida útil. Ribeiro et al. (2016, p. 41), confirmam que isso proporciona a redução no consumo de matérias-primas por meio da reciclagem e reutilização de materiais, reduzindo consecutivamente o volume de resíduos descartados e os custos agregados ao setor.

O presente artigo vem com o intuito de propor à indústria da construção civil a forma mais adequada de reutilizar o resíduo de cerâmica vermelha e reinseri-lo na própria cadeia produtiva. E assim, reduzir danos.

\section{MATERIAL E MÉTODO}

\section{O MUNICÍPIO DE CRICIÚMA}

O universo deste artigo é o município de Criciúma, situado na planície litorânea, no extremo sul de Santa Catarina, a 144,86 km da capital, Florianópolis. É a cidade mais populosa do Sul Catarinense, estima-se sua população atual, conforme o censo 2012 do IBGE, em cerca de 202.395 habitantes. Tem uma extensão de 209,8 km², 2,23\% da área do estado, além de ser a principal cidade da Região Metropolitana Carbonífera.

Atualmente, o município é um centro econômico muito importante, por ser polo nos setores das indústrias de plásticos, química, metal-mecânica, confecção, cerâmica, colorifícios e extração mineral. (SINDUSCON Criciúma 2006, p. 7).

\section{MÉTODO}

A pesquisa realiza-se em quatro etapas. A primeira delas consiste em identificar, através de pesquisas bibliográficas, qual o RCD descartado em maior volume no município de Criciúma, SC. Após essa identificação, parte-se para o segundo passo que se trata de um levantamento literário acerca das possibilidades de reutilização do referido RCD. Na etapa subsequente, as informações obtidas até então são organizadas, catalogadas e alisadas. E a última etapa refere-se à conclusão do trabalho. Com todos os dados das etapas anteriores em mãos apresentam-se os resultados.

O fluxograma da Figura 1 demonstra, de forma sucinta, as etapas discorridas acima:

Figura 1 - Fluxograma: Etapas da pesquisa 


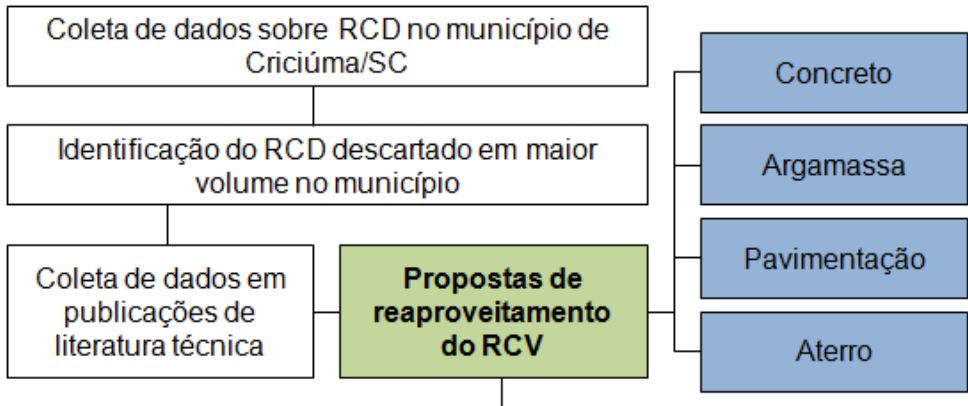

Método mais adequado para reutilizar o RCD

Fonte: Do autor (2014)

\section{REAPROVEITAMENTO DE CERÂMICA VERMELHA REAPROVEITAMENTO NO CONCRETO}

Wada (2010) estudou a adição de resíduo de cerâmica vermelha (RCV) da construção civil na composição de concretos, em substituição do agregado miúdo, buscando a sua utilização em estacas do tipo moldadas in loco. Os estudos foram realizados no laboratório da Faculdade de Engenharia da Universidade Estadual Paulista, na cidade de Ilha Solteira. Foram confeccionadas três estacas de concreto com $40 \%$ de RCV. Os ensaios em laboratório mostraram que em substituição acima de $40 \%$ de RCV o concreto torna-se inviável, pois necessitaria de um aumento muito grande na quantidade de aditivo para se obter o abatimento desejado. Com teores de $40 \%$ de substituição, aos 28 dias, o concreto já apresentava resistência característica requerida para estacas, que é de fck=18 MPa.

Os ensaios demonstram que houve uma melhora nas propriedades mecânicas do concreto, isso ocorreu devido ao efeito filler do RCV, que atua na estrutura do concreto, ocupando os espaços vazios deixados pelos grãos maiores. Wada (2010) concluiu com os resultados obtidos, que o concreto com adição de resíduo de cerâmica vermelha apresenta plenas condições de uso na confecção de estacas moldadas in loco.

Na Universidade Federal do Rio Grande do Sul, Bicca (2000) estudou a viabilidade do uso do rejeito cerâmico como substituição do agregado graúdo na produção de concreto com características estruturais. O trabalho foi feito com materiais provenientes de indústrias cerâmicas de Gravataí, região metropolitana de Porto Alegre.

$\mathrm{O}$ estudo baseou-se em determinações experimentais da resistência à compressão, da resistência à tração por compressão diametral, absorção de água, o desgaste e o módulo de deformação estática, utilizando-se em referência de comparação um concreto convencional, produzido com brita basáltica (BICCA, 2000, p. 11). 
Um ponto importante salientado pelo autor é a alta absorção do agregado cerâmico, por ser um material poroso. Os testes de absorção de água demonstram que em torno de $90 \%$ da absorção total em 24 horas se dá dentro de 2 minutos. Por isso, é indicado o umedecimento prévio do agregado, para evitar a falta de água durante o amassamento do concreto ou então compensar a água de absorção por ocasião do amassamento do concreto. Este procedimento, segundo o autor, também promove uma melhor aderência da pasta, uma vez que evita o acúmulo de água nos poros superficiais do agregado.

Bicca (2000) concluiu que concretos estruturais podem ser viáveis com substituição de $20 \%$ do agregado graúdo por RCV. Além das vantagens ambientais, a cerâmica vermelha causa menos desgaste aos equipamentos usados para o fracionamento de agregados.

Brito et al. (2004), assim como Bicca, também salientam a alta absorção do agregado cerâmico. Os autores estudaram a substituição do agregado graúdo em concretos não estruturais por resíduo de cerâmica vermelha. Brito et al. (2004) também indicam um procedimento de pré-saturação do agregado cerâmico, que pode ser realizado no próprio canteiro de obras. O procedimento consiste na imersão do agregado durante 30 minutos em água. Após este tempo, os autores recomendam deixá-lo secar por mais 30 minutos sobre papel, para que a água absorvida em excesso seja retirada.

Quanto aos resultados da substituição do agregado graúdo em concretos por resíduo de cerâmica vermelha, Brito et al. (2004), concluem que o percentual de $33 \%$ de substituição é o mais adequado, após analisar o desempenho mecânico, em termos de resistência à compressão e à tração. Um ponto que vale salientar, é que, segundo os autores, a resistência à abrasão dos concretos produzidos com agregados de cerâmica vermelha, mostrou-se maior que do concreto de referência.

O uso de resíduos de cerâmica vermelha como substituto parcial do cimento Portland em concretos também tem sido objeto de pesquisas recentes. Gonçalves (2007) realizou estudo experimental utilizando cerâmica vermelha na substituição de $20 \%$ do cimento em concretos. Este percentual foi obtido através de estudos, onde se verificou que valores acima de $20 \%$ comprometiam a resistência do concreto. Os autores estudaram o comportamento tensão versus deformação, resistência à compressão, resistência à tração na flexão e por compressão diametral. Após os ensaios verificaram que com a substituição de $20 \%$ de cimento pelo resíduo cerâmico houve uma redução do módulo de elasticidade do concreto. Com relação à resistência à compressão, 
resistência à tração por compressão diametral e a resistência à tração na flexão dos concretos aos 28 dias, o resíduo não influenciou significativamente os resultados, independente da relação água/cimento utilizada. Gonçalves (2007) então concluiu que o concreto com substituição do cimento por resíduo cerâmico é uma alternativa para o aproveitamento do resíduo cerâmico.

Os percentuais de substituição indicados por cada autor, para reaproveitamento da cerâmica vermelha em concretos, encontram-se dispostos na tabela 1.

Tabela 1 - Resumo dos estudos sobre reaproveitamento em concreto

\begin{tabular}{c|c|c}
\hline Autor & Material Substituído & $\begin{array}{c}\text { \% de substituição } \\
\text { indicado }\end{array}$ \\
\hline WADA (2010) & $\begin{array}{c}\text { Agregado miúdo em concreto para } \\
\text { estacas }\end{array}$ & 40 \\
\hline BICCA (2000) & $\begin{array}{c}\text { Agregado graúdo em concreto } \\
\text { estrutural }\end{array}$ & 20 \\
\hline BRITO (2004) & $\begin{array}{c}\text { Agregado graúdo em concreto não } \\
\text { estrutural }\end{array}$ & 33 \\
\hline GONÇALVES (2007) & Cimento Portland em concreto & 20 \\
\hline
\end{tabular}

Fonte: Do autor, 2014.

\section{REAPROVEITAMENTO EM ARGAMASSAS}

Na Universidade Federal de Pernambuco, Alcantara e Nóbrega (2011) realizaram estudos substituindo o agregado miúdo de argamassa de revestimento por um percentual de resíduo de cerâmica vermelha (CV). O trabalho focou na substituição do rejeito de $\mathrm{CV}$ visando à obtenção do efeito filler e atividade pozolânica.

Efeito filler é definido pelo preenchimento dos vazios entre as partículas do cimento por grãos, aumentando assim a capacidade do material e a sua resistência. É justamente esta característica que se busca nos estudos de adição de material cerâmico moído (WADA, 2010, p 34).

A atividade pozolânica que o material cerâmico pode produzir é indício de que é possível substituir parte do cimento Portland ou do agregado. Isto porque, na presença de água e de cal hidratada, o material pozolânico adquire características cimentícias, ponto de muito interesse, no que tange as suas propriedades de resistência.

Como o material coletado para o estudo apresentou pozolanicidade insuficiente para substituir o cimento Portland, os ensaios foram realizados substituindo o agregado miúdo pelo resíduo de CV em teores de substituição de 10, 15, 20 e 30\%.

Para os ensaios no estado endurecido foram moldados 12 corpos de prova para cada teor de substituição, sendo realizados ensaios de resistência em 7, 28, 56 e 90 dias 
(3 amostras por idade). Os resultados mostraram que a resistência à compressão aumenta proporcionalmente o índice de substituição. As autoras relacionam o aumento de resistência ao efeito filler proporcionado pela fina granulometria dos resíduos.

Os ensaios de laboratório realizados pelas autoras demonstraram que o teor ideal de substituição do agregado fino por resíduo de cerâmica vermelha em argamassas de revestimento é de $20 \%$.

No Laboratório de Materiais e Técnicas Construtivas, da Universidade Eduardo Mondlane em Moçambique, Dias (2013) elaborou estudos para verificar a possibilidade de substituir parcialmente o cimento por cerâmica vermelha em argamassas e também na produção de blocos de alvenaria.

Para tal, foram utilizados resíduos de cerâmica vermelha gerados durante a produção e transporte de blocos cerâmicos provenientes de uma indústria da região de Maputo.

O ensaio de índice de atividade foi elaborado com substituição do cimento Portland por 20, 25, 30 e 35\% de material cerâmico. Os resultados do teste em 45 dias demonstram que ocorre um aumento da resistência mecânica à compressão das misturas estudadas. Isto mostra que há um desenvolvimento da resistência com o aumento do período de cura. Aos 45 dias, pode-se observar que a absorção de água diminui para as misturas com adição de cerâmica. Segundo o autor, este resultado se deve à reação entre o hidróxido de cálcio proveniente da pasta do cimento hidratado e o resíduo de cerâmica. A adição do resíduo preenche os espaços vazios, diminuindo assim a permeabilidade. Esta característica ajuda na melhora da durabilidade da pasta e é confirmada também pelo aumento de resistência mecânica ao longo do tempo de cura, mostrado nos ensaios de índice de atividade.

Quanto aos ensaios de resistência à compressão, as misturas com 20, 25 e 30\% de substituição, respectivamente, apresentaram resistência à compressão ligeiramente maior que a amostra de controle. As misturas apresentam valores de resistência à compressão na faixa exigida pela norma NBR 6136 (1994).

Através de tratamento estatístico de resistência à compressão das amostras, o autor indica o percentual de $20 \%$ de substituição do cimento Portland na produção de argamassas para blocos de concreto para alvenaria, pois esta apresentou os melhores resultados.

Os percentuais de substituição indicados por cada autor, para reaproveitamento da cerâmica vermelha em argamassas, encontram-se dispostos na tabela 2. 
Tabela 2 - Resumo dos estudos sobre reaproveitamento em argamassa

\begin{tabular}{c|c|c}
\hline Autor & Material Substituído & $\begin{array}{c}\text { \% de substituição } \\
\text { indicado }\end{array}$ \\
\hline $\begin{array}{c}\text { ALCANTARA e } \\
\text { NÓBREGA (2011) }\end{array}$ & $\begin{array}{c}\text { Agregado miúdo em argamassa de } \\
\text { revestimento }\end{array}$ & 20 \\
\hline DIAS (2013) & $\begin{array}{c}\text { Cimento em argamassa para bloco de } \\
\text { alvenaria }\end{array}$ & 20 \\
\hline
\end{tabular}

Fonte: Do autor, 2014.

\section{REAPROVEITAMENTO NA PAVIMENTAÇÃO}

A utilização de RCD em pavimentação é bastante conhecida no Brasil e no mundo, porém a opção de utilizar apenas cacos de tijolos e telhas em camadas estruturais de pavimentos ainda é pouco explorada (REDIVO, 2011, p. 61).

Redivo (2011) elaborou análise sobre o comportamento entre misturas de solo e resíduo de cerâmica vermelha, visando seu emprego em camadas de pavimentos de rodovias e ruas com baixo volume de tráfego.

Os estudos de laboratório foram realizados na Universidade Federal de Santa Catarina (UFSC) e também nos laboratórios da Universidade do Sul de Santa Catarina (UNISUL).

Os resíduos de cerâmica vermelha provieram da região de Morro da Fumaça, sul de Santa Catarina. Já as amostras de solo foram coletadas de três jazidas diferentes nos municípios de Gravatal, Tubarão e Criciúma, por se tratarem de solos comumente usados em camadas de reforço, sub-base e base dos pavimentos da região.

Para a fragmentação do resíduo, o autor aconselha a utilização de rolos compactadores, pois tal procedimento pode ser realizado no canteiro de obras, agilizando o processo e também diminuindo os custos já que não necessita de britadores específicos para a fragmentação do resíduo. O autor indica ainda o uso do rolo compactador do tipo pé de carneiro, por ter se mostrado mais eficiente na fragmentação dos cacos de cerâmica, em relação ao rolo liso, dando ao material uma granulometria adequada para as misturas com solo.

Após os ensaios em laboratório com as misturas solo-agregado, o autor concluiu que a quebra do material cerâmico, após a compactação das amostras, é menor nas misturas realizadas com os solos de Tubarão e Criciúma do que nas misturas compostas pelo solo de Gravatal. Pois estes solos possuem uma granulometria mais fina que o solo de Gravatal, o que acaba gerando uma melhor acomodação do agregado dentro do solo 
e uma consequente proteção das partículas com relação às cargas de compactação aplicadas na mistura (REDIVO, 2011, p. 112). Além disso, o material cerâmico proporcionou para as misturas, com solos de Tubarão e Criciúma, um aumento considerável de qualidade, aumento do CBR e redução dos valores de expansão.

Para o dimensionamento do pavimento de uma rodovia com baixo volume de tráfego, a partir dos resultados de CBR e Módulo de Resiliência, o autor decidiu utilizar a mistura composta por $50 \%$ de solo e $50 \%$ de cacos de telhas para a implantação e pavimentação da Rua Hilário José de Mello, com 456 m de extensão, no município de Tubarão, SC.

Após comparação com o orçamento inicial do pavimento, realizado pela prefeitura municipal de Tubarão e orçamento elaborado pelo autor, utilizando misturas solo-agregado para camada de sub-base com resíduos de telhas, Redivo (2011) afirma que é possível gerar uma economia de $20 \%$ no custo final da estrutura, além de reaproveitar grande quantidade de material cerâmico.

Dias (2004), através da Universidade de São Paulo (USP), realizou análise de misturas contendo solo e agregados reciclados de telhas de cerâmica vermelha (ART), gerados nas cidades de Monte Carmelo e Ituiutaba, estado de Minas Gerais, aplicado em pavimentos de baixo volume de tráfego.

A princípio o autor buscava o emprego do agregado no seu estado primário em camadas de base, porém, após análises em laboratório, concluiu que aplicar somente o agregado de ART na camada em questão seria impraticável. Dias (2004) propôs então uma metodologia de otimização das misturas, unindo o agregado de ART com solo laterítico. A escolha deste tipo de solo, segundo o autor, seria em decorrência do sucesso da aplicação do mesmo em camadas de pavimentos.

Os resultados de laboratório feitos com a mistura solo-agregado mostraram que os valores de CBR ficaram dentro da faixa utilizada em pavimentos de baixo volume de tráfego e a mistura mostrou ganhos expressivos no valor do módulo de resiliência, que era limitado para o emprego do ART em estado primário (Dias, 2004, p. 211).

Segundo Dias (2004), o percentual a ser utilizado na mistura de ART e solo laterítico deve ser de $63 \%$ e $37 \%$, respectivamente.

É preciso salientar que o autor não aplicou em campo a mistura e indica que sejam elaboradas experiências de campo para avaliação da mistura em condições reais de solicitação para conhecimento do seu desempenho ao longo do tempo. 
Os percentuais de substituição indicados por cada autor, para reaproveitamento na pavimentação em misturas solo-agregado, encontram-se dispostos na tabela 3.

Tabela 3 - Resumo dos estudos sobre reaproveitamento em pavimentação

\begin{tabular}{c|c|c}
\hline Autor & Material Substituído & $\begin{array}{c}\text { \% de RCV na } \\
\text { mistura }\end{array}$ \\
\hline REDIVO (2011) & $\begin{array}{c}\text { Agregado em mistura de solo- } \\
\text { agregado para camada de sub-base }\end{array}$ & 50 \\
\hline DIAS (2004) & $\begin{array}{c}\text { Agregado em mistura de solo- } \\
\text { agregado para camada de base }\end{array}$ \\
\hline
\end{tabular}

Fonte: Do autor, 2014.

\section{REAPROVEITAMENTO EM ATERROS}

Segundo dados coletados por Alcantara e Nóbrega (2011, p. 1), uma única olaria produz em média 240 mil peças cerâmicas por mês, das quais são descartados 55 mil kg de rejeitos, que geralmente são utilizados como aterros em terraplenagem.

Redivo (2011) destaca que, na região de Morro da Fumaça, o material de cerâmica vermelha descartado por quebras ou defeitos nas indústrias de tijolos e telhas acaba sendo utilizado como aterro no próprio pátio das indústrias, ou ainda, como aterro em valas de drenagem. As empresas também utilizam o material para a conservação de estradas que dão acesso a jazidas de extração de matéria prima. Porém, esse tipo de revestimento tem pouca duração, já que o material cerâmico se quebra facilmente com o tráfego ao ponto de se tornar pó em pouquíssimo tempo.

Bicca (2000, p. 36) constata que nas regiões em que os agregados naturais ainda são economicamente viáveis, e isto implica em concessão de lavra, transporte, etc., o rejeito cerâmico é utilizado tão somente na execução de aterros e outros tipos de serviços.

Wada (2010, p. 29) observa que os RCDs em geral, sem passar por um processo de beneficiamento, vêm sendo utilizados empiricamente em vários centros urbanos. A autora cita que na cidade de Belo Horizonte, MG, existe um aterro sanitário em que o resíduo da construção e demolição (sem passar por um processo de beneficiamento) tem sido utilizado como camada de cobertura diária, porém, com acompanhamento e avaliação da compactação deste material.

\section{RESULTADOS E DISCUSSÕES}


A busca por modelos de produção mais sustentáveis e o consumo de recursos naturais não renováveis culmina em pesquisas que desenvolvem estratégias de reciclagem e novas tecnologias com base na reutilização de resíduos da construção civil, gerados muitas vezes por falha no processo construtivo.

$\mathrm{Na}$ cidade de Criciúma, dentre os resíduos gerados pela construção civil, destaca-se em maior quantidade o RCV.

É preciso ressaltar que além dos volumes de RCV gerados pela construção civil e demolições, no município, também é gerado um grande volume desse material nas indústrias de cerâmica da região de Morro da Fumaça. Segundo Redivo (2011, p. 39), são produzidos cerca de 100 milhões de peças de tijolos e telhas por mês nas indústrias da região de Morro da Fumaça e desse total 5\% são descartados por defeito ou falhas no manuseio. Com este total de resíduos, o autor considera ser possível pavimentar $8 \mathrm{~km}$ de camada de sub-base com $20 \mathrm{~cm}$ de espessura por mês na região.

Nesse trabalho foram analisadas pesquisas voltadas para a reutilização do resíduo de cerâmica vermelha (RCV), com a intenção de reinseri-lo no ciclo de produção da construção civil, através de materiais de construção como: concretos estruturais e não estruturais, argamassas de revestimento, blocos de alvenaria, em substituição, ainda que pequena, do cimento e como agregado na pavimentação.

Para propor a forma mais adequada de reutilização do RCV, dentre os estudos apontados, optou-se por seguir algumas diretrizes, que servem como balizadores para escolha:

- Os materiais produzidos devem atender às exigências físicas, mecânicas, químicas e ambientais das normas, e devem ser resistentes, duráveis e trabalháveis, para que sejam superiores ou similares aos produtos já existentes no mercado (BASTOS et al. 2013, p. 9);

- Adequação do RCV, devido à variabilidade na composição do material em cada região onde ele é produzido, o que poderá influenciar nos produtos onde o mesmo será empregado;

- Facilidade de manuseio, beneficiamento e economia do RCV para emprego em produtos de construção civil - principalmente devido à cidade de Criciúma não possuir uma usina de triagem e reciclagem de resíduos da construção e demolição;

- Produto com maior quantidade de volume de utilização de RCV incorporado.

\section{CONCLUSÕES}


Este estudo teve como objetivo propor uma forma de reutilização do RCV em materiais de construção no município de Criciúma, com base na avaliação das pesquisas realizadas reutilizando esse material.

Através das análises realizadas, e dos pontos citados no item anterior, conclui-se que para o município de Criciúma uma forma de empregar o resíduo de $\mathrm{CV}$ seria em base e sub-base de pavimentos rodoviários de tráfego leve, mais especificamente para sub-base em misturas de solo-agregado.

$\mathrm{O}$ uso do RCV em concretos e argamassas empregaria um volume de reutilização de cerâmica vermelha inferior ao volume utilizado em pavimentação. Para esta finalidade é necessário um controle de qualidade na fabricação, o que dificulta sua fabricação tanto em usina como no canteiro de obra, podendo trazer problemas no que se refere ao atendimento às normas.

Para a aplicação do RCV em aterros, deve-se pensar em utilizá-lo desta forma somente quando este não mostrar potencial de reutilização.

Para que o uso do RCV em pavimentação seja viável, é preciso que os setores da construção civil, indústrias de cerâmica vermelha e órgãos públicos atuem em parceria de forma sustentável. As construtoras precisam da conscientização para que ocorra a separação dos diferentes materiais gerados no canteiro de obras. Os órgãos públicos devem incentivar a implantação de usinas de triagem dos RCDs, beneficiando a logística, gerenciamento e distribuição do resíduo, e empresas de pavimentação utilizem-no como agregado em pavimentação.

É interessante novo estudo para a avaliação da viabilidade econômica do agregado de cerâmica vermelha no município de Criciúma.

\section{REFERÊNCIAS}

ALCANTARA, P. S. X; NÓBREGA, A. C. V. Desenvolvimento de argamassas para revestimento utilizando resíduos de cerâmica vermelha de Caruaru/PE como material pozolânico e/ou agregado alternativo. 2011. $8 \mathrm{f}$. TCC (artigo de conclusão de curso) - UFP, Caruaru-PE.

BASTOS R. S. et al. Revisão Bibliográfica dos Estudos Sobre a Aplicação da Lama do Beneficiamento de Rochas Ornamentais na Produção de Materiais de Construção. In: CONGRESSO BRASILEIRO DO CONCRETO, 54, 2013, Gramado. Anais... São Paulo: Instituto Brasileiro do Concreto, 2013. 
BICCA, I. DA S. Estudo da viabilidade de utilização do rejeito cerâmico, como agregado graúdo, na produção de concreto com características estruturais. 2000. 98 f. Dissertação (Mestrado em Engenharia Civil) - Programa de Pós-Graduação em Engenharia Civil, UFRGS, Porto Alegre, 2000.

BRITO J. et al. Mechanical behaviour of non-structural concrete made with recycled ceramic aggregates. 2004, 5 f. Technical University of Lisbon, Portugal.

BUSTAMANTE, G. M.; BRESSIANI, J. C. A Indústria Cerâmica Brasileira. Revista Cerâmica Industrial, v. 5, n. 3, Mai-jun. 2000; Disponível em:<http://www.ceramicaindustrial.org.br>. Acesso em 19 abr. 2014.

CABRAL, A. E. B. et al. Determinação da influência do tipo de agregado reciclado de resíduo de construção e demolição sobre o módulo de deformação de concretos produzidos com agregados reciclados. Revista IBRACON de estruturas e materiais, São Paulo,v. 01, n.2, p.171-192, junho 2008.

CAMPOS, C. F. S. et al. Analise das propriedades físicas e mecânicas do concreto produzido com resíduo sólido de cerâmica vermelha. Revista Colloquium Exactarum, Presidente Prudente, v. 04, n.2, p.01-11, jul/ago 2007.

CARDOSO, A. da C. F. Estimativa de geração de resíduos da construção civil nos municípios de Criciúma e Içara e estudo de viabilidade de usinas de triagem e reciclagem. 2011. 107 f. TCC (monografia de conclusão de curso) - UNESC, Criciúma/SC.

CONSELHO NACIONAL DO MEIO AMBIENTE (CONAMA). Resolução n. 307, de 05 de julho de 2002. Estabelece diretrizes, critérios e procedimentos para a gestão dos resíduos da construção civil. Disponível em: <http://www.mma.gov.br/port/conama/res/res02/res30702.html>. Acesso em: 20 abr. 2014.

DIAS, A. T. Incorporação de resíduos de cerâmica vermelha como adição pozolânica na substituição parcial do cimento em argamassas. 2013. 58 f. TCC (monografia de conclusão de curso) - Universidade Eduardo Mondlane, Maputo.

DIAS, J. F. Avaliação de resíduos da fabricação de telhas cerâmicas para o seu emprego em camadas de pavimento de baixo custo. São Paulo, 2004. Tese (Doutorado) - Escola Politécnica, Universidade de São Paulo, 2004.

FORTUNA, J.; MARQUES, J. A.; BIASI, L. H. de; ROSSO, P.; BETIOLI, A. M. Diagnóstico dos resíduos de construção civil em construtoras de Criciúma/SC. Rev.Técnico Científica (IFSC), Coqueiros, v.3, n.1, p.110-116, 2012.

GONÇALVES, J. P. Utilização do resíduo da indústria cerâmica para produção de concretos. Revista Escola de Minas, Tubarão, v.60, n.4, p.639-644, oct./dez. 2007.

INSTITUTO BRASILEIRO DE GEOGRAFIA E ESTATÍSTICA (IBGE). Pesquisa anual da indústria da construção. Disponível em: <http://www.ibge.gov.br/home/estatistica/economia/industria/paic/2008/comentario.pdf $>$. Acesso em: 24 ago. 2012.

JOHN, V.M.; AGOPYAN, V. Reciclagem de resíduos da construção. In: Seminário de Reciclagem e Resíduos Sólidos Domésticos. São Paulo: SP. 2000.

PETERLE, Everton Conti; GUADAGNIN, Mário Ricardo. Diagnóstico Ambiental dos Resíduos da Construção Civil e demolição no município de Criciúma: Análise setorial de empresas afiliadas ao SINDUSCON. Criciúma, Dez. 2006. 
PINTO, T. de P. Entulho de Construção: Problema Urbano que Pode Gerar Soluções. São Paulo. Ed. Pini, 1992.

PINTO, T. de P. Perda de materiais em processos construtivos tradicionais. São Carlos: Departamento de Engenharia Civil da Universidade Federal de São Carlos, 1989. $33 \mathrm{p}$.

REDIVO, I. M. Utilização de resíduo de cerâmica vermelha em misturas com solo para construção de camadas de pavimentos com baixo volume de tráfego. 2011. 160f. Dissertação (Mestrado em Engenharia Civil) - Universidade Federal de Santa Catarina, Florianópolis, 2011.

RIBEIRO, D.; MOURA, L.S.. Revista de Ciência Gerenciais. Sustentabilidade: Formas de Reaproveitar os Resíduos da Construção Civil, São Paulo, v.20, n.31, p.41-45, 2016.

ROSA, F. R. Identificação e cadastramento de áreas de descarte de resíduos de construção e demolição na região da AMREC, Santa Catarina. 2011. 109 f. TCC (monografia de conclusão de curso) - UNESC, Criciúma/SC.

SINDICATO DAS INDUSTRIAS DA CONTRUÇÃO E DO MOBILIARIO DE CRICIÚMA (SINDUSCON). Diagnóstico dos RCD's e Plano de gerenciamento dos resíduos da construção e demolição de Criciúma/SC - PIGRCD. 2006.

WADA, P. H. Estudo da incorporação de resíduo de cerâmica vermelha na composição de concreto para uso em estacas moldadas in loco. 2010. $108 \mathrm{f}$. Dissertação (Mestrado em Engenharia Civil) - Faculdade de Engenharia, Universidade Estadual Paulista, Ilha Solteira, 2010. 